\title{
The impact of the curing process on the efflorescence and mechanical properties of basalt fibre reinforced fly ash-based geopolymer composites
}

\author{
Kinga Korniejenko ${ }^{1}$, Dariusz Mierzwiński ${ }^{1, *}$, Roland Szabó $^{2}$, Nóra Papné Halyag $^{2}$, Petr \\ Louda $^{3}$, Eythor Rafn Thorhallsson ${ }^{4}$, and Gábor Mucsi ${ }^{2}$ \\ ${ }^{1}$ Cracow University of Technology, Institute of Material Engineering, Faculty of Material \\ Engineering and Physics, , Warszawska 24, 31-155, Cracow, Poland \\ ${ }^{2}$ University of Miskolc, Institute of Raw Material Preparation and Environmental Processing, 3515, \\ Miskolc, Egyetemváros, Hungary \\ ${ }^{3}$ Technical University of Liberec, Faculty of Mechanical Engineering, Department of Material \\ Science, Studentska 2, Liberec, 461 17, the Czech Republic \\ ${ }^{4}$ Reykjavik University, Civil Engineering, Menntavegur 1, IS-101, Reykjavik, Iceland
}

\begin{abstract}
Efflorescence is one of the limitations of the widespread use of geopolymers. This problem is caused by excess unreacted sodium oxide remaining inside materials. Unreacted sodium oxide creates white efflorescence on the surface of the produced material in the form of sodium carbonate heptahydrate $\mathrm{Na}_{2} \mathrm{CO}_{3} \cdot 7 \mathrm{H}_{2} \mathrm{O}$. It decreases not only the aesthetic value of the final products, but also the mechanical properties of the material. The aim of this article is to analyse the influence of the curing method on the appearance of efflorescence on geopolymer composites reinforced by short basalt, especially on mechanical properties. Class F fly ash from the 'Skawina' coal-fired power plant (located in Skawina, Lesser Poland, Poland) was used as raw material for the geopolymerization process. The article compares two methods of curing: typical laboratory conditions (in the air) and samples submerged in water. Three series of fly ash-based geopolymer were cast: basalt fibres were added as $1 \%$ and $2 \%$ by weight of fly ash and one control series without any fibres. The investigation was performed using visual analysis, including microstructure investigation, and the testing of mechanical properties (compressive strength at ambient temperature) after 28 days.
\end{abstract}

\section{Introduction}

Geopolymers are attractive for industrial applications from several perspectives: environmental protection (decrease of $\mathrm{CO}_{2}$ emission and energy consumption during the production process), the effectiveness of the manufacturing process and the simplicity of application $[1,2]$. They have low levels of shrinkage and high adhesion interaction to such

*Corresponding author: dariusz.mierzwinski@pk.edu.pl 
materials as concrete, steel, glass and ceramics, and they have attractive mechanical properties and possibilities for application in different conditions because of their chemical resistance to atmospheric conditions and to a variety of acids, salts and fire [3, 4]. Despite these advantages the use of geopolymers is still low compared to Portland cement concrete [5]. One of the most significant limitations for the application of geopolymers is the formation of efflorescence on the surface of the materials $[6,7]$.

The efflorescence of geopolymers is a relatively complex physicochemical process [8]. It is mainly caused by excess sodium oxide remaining unreacted. The unreacted sodium oxide creates white efflorescence on the surface of the produced material in the form of sodium carbonate heptahydrate $\mathrm{Na}_{2} \mathrm{CO}_{3} \cdot 7 \mathrm{H}_{2} \mathrm{O}[5,9]$. The mechanism of efflorescence is connected with the migration of ions from inner pores to the surface of the materials, where they react with $\mathrm{CO}_{2}$ and water $[10,11]$. The most significant reason for the efflorescence of the geopolymer is usage of a high concentration of an alkaline solution as an activator in the preparation process (the unreacted alkaline substance in the geopolymer is diffused to its surface) $[9,12]$. Because of this, the efflorescence is of greater intensity in wet conditions $[9,13]$.

Moreover, the efflorescence is not only an aesthetic problem (Fig. 1), but it could also have an impact upon the mechanical properties of the material [14-16] as well as damaging the protective layer around the steel reinforcement $[15,17]$.
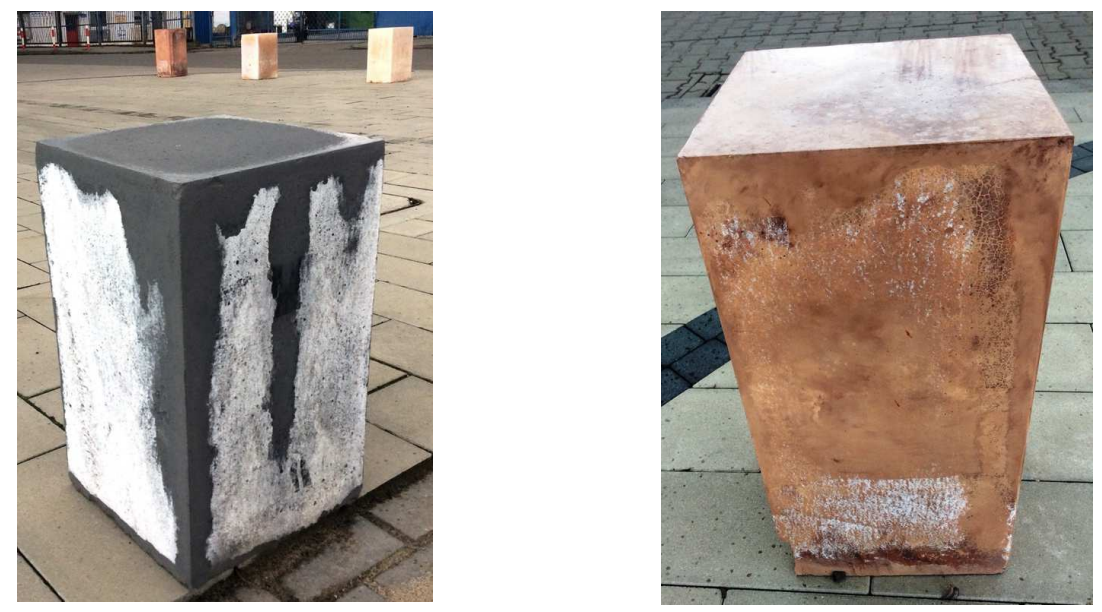

Fig. 1. Efflorescence on geopolymer bollards around a parking area (Cracow, Poland)

The appearance of efflorescence is dependent upon many factors, such as raw material composition, the curing process, including temperature and the type of alkali activator [15, 18]. In the literature, there are three groups of methods for the reduction the efflorescence on geopolymers:

- application of additives;

- modification of the surface of the material;

- modification of the process, including curing of the materials.

One of the ways of reducing the efflorescence is by adding an appropriate amount of active aluminium or enhancing the release of aluminium from the less active precursor by adjusting the curing conditions [19]. It was found that adding calcium aluminate cement to the geopolymer could inhibit the efflorescence [20, 21] as could other alumina-rich additives such as natural pozzolana or zeolites [15, 22] and nano- $\mathrm{SiO}_{2}$ [10]. Others additives eliminate or limit the efflorescence effect through $\mathrm{pH}$ reduction, such as: coffee grounds [14]. 
Another possibility for avoiding efflorescence is surface modification [22, 23]. If the surface of the geopolymer becomes hydrophobic, the leaching of water-soluble alkali ions is significantly reduced.

A promising way of limiting efflorescence is modification of the production process [24-26]. This could take the form of reducing the fluidity of alkali through the control of its microstructure and chemistry [12], increasing the curing temperature [12] or hydrothermal processing during alkali-activated material production (in an autoclave) [5]. All of these methods significantly reduce the appearance of efflorescence on the surfaces of the material.

The main objective of the article is to analyse the influence of the curing method on the appearance of efflorescence on geopolymer composites reinforced by short basalt fibres (length of around $5 \mathrm{~mm}$ ), especially on mechanical properties such as compressive strength. The behaviour of sodium activators on synthesized fly ash geopolymers containing basalt fibre has been analysed.

\section{Materials and methods}

\subsection{Materials}

The geopolymer composite based on fly ash was delivered from the bituminous coal-fired power plant 'Skawina' (located in Skawina, Lesser Poland, Poland). The matrix was made from fly ash without the addition of aggregate. The chemical and physical properties are suitable for geopolymer synthesis. The composition of this fly ash is characteristic for class F [27]. It is comprised of up to $5 \%$ unburned material, less than $10 \%$ of iron compounds and a low amount of calcium compounds. The amount of the reactive silica is around $36 \%$. This is an acceptable value for geopolymer synthesis. The physical parameters of the fly ash also supported geopolymerization, including the content of particles under the size of $45 \mu \mathrm{m}$ is ca. 88\% [27, 28]. This supports the reactivity of the raw material. The fly ash is comprised of a large amount of spherical particles (Fig. 2a) and because of this, it has good workability. Research of the mineralogical structure shows a large amount of amorphous phase [28], which is also is beneficial for the geopolymerization process.
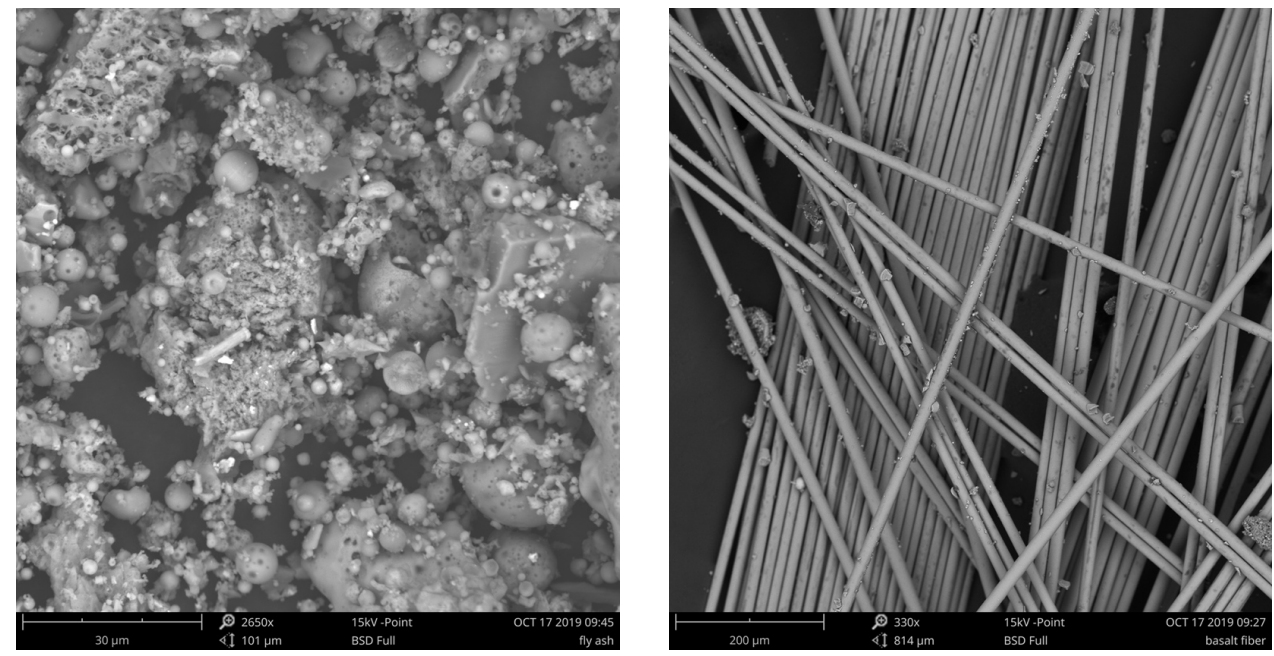

Fig. 2. SEM image: a) fly ash b) basalt fibres 
The matrix was reinforced by the short basalt fibres (ca. $5 \mathrm{~mm}$ length) - Fig. 2b. The fibres were added at the amount of $1 \%$ and $2 \%$ by weight.

\subsection{Samples preparation}

Samples were prepared using fly ash, basalt fibres and an $8 \mathrm{M}$ ratio sodium hydroxide solution. The fly ash, alkaline solution and fibres were manually mixed for around 5 - 10 minutes to obtain a homogeneous paste. Three kinds of composites were prepared:

- samples without fibres (geopolymer mortar);

- samples with $1 \%$ short basalt fibres by weight;

- samples with $2 \%$ short basalt fibres by weight.

The homogeneous paste was then poured into sets of plastic moulds and was formed by hand. The composites were left in laboratory conditions for $24 \mathrm{~h}$. After this time, there were heated in the laboratory drying cabinet for $8 \mathrm{~h}$ at $75^{\circ} \mathrm{C}$ and cooled with the drying cabinet. Next, the samples were unmoulded. Two methods of curing were applied - typical laboratory condition (in the air) and samples submerged into distilled water (3 weeks submerged and then dried for 1 week).

Additionally, for visual observation three samples were put into the distilled water and half submerged. All of samples were subjected to a compressive strength test after 28 days.

\subsection{Analytical procedure}

For the morphology investigation, the scanning electron microscope (SEM) on Phenom ProX was used. The research was conducted on samples that were previously broken during compressive strength tests at various magnifications.

Compressive strength tests were performed according to the methodology described in standard EN 12390-3 ('Testing hardened concrete. Compressive strength of test specimens') because of the lack of existing standards dedicated for geopolymer materials. The tests involved at least five samples. Tests were made on the Anyagvizsgáló Készülékek Gyára Budapest, type: SZF-1 universal testing machine with the Hottinger Baldwin Messtechnik GmbH measurement device:. Samples used in the compressive strength test were $20 \mathrm{~mm}$ cubes.

\section{Results}

\subsection{Visual observation for efflorescence}

The investigation was performed with the visual analysis of three kinds of samples. The efflorescence appeared only on the half-submerged samples (Fig. 3) and more sodium carbonate heptahydrate occurred on the samples with increases in time. No relationship was found between the addition of basalt fibres and the amount of the efflorescence. 

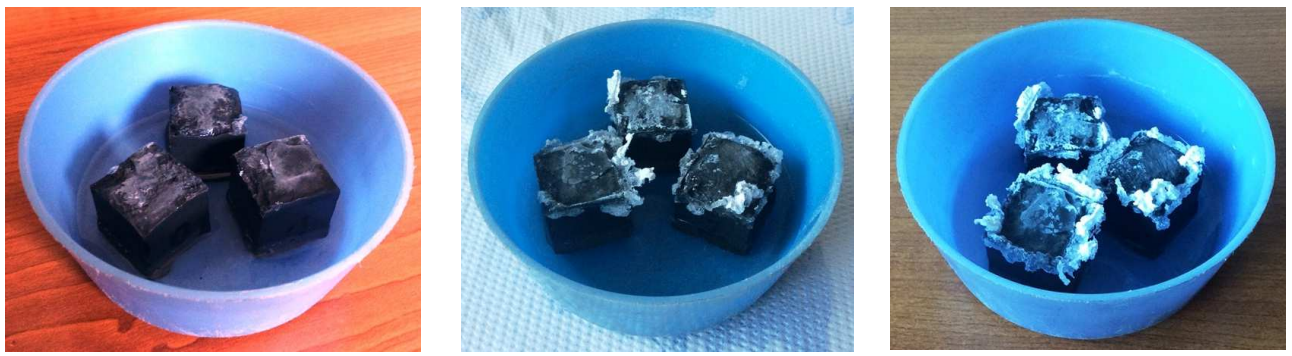

Fig. 3. The efflorescence on the samples half submerged after: a) 2 weeks, b) 3 weeks, and c) 1 month

Efflorescence did not appear on the samples cured in the typical laboratory condition (in the air) or on the samples submerged in water.

\subsection{Microstructure investigation}

The SEM investigations were made for fly ash and fibres (Fig. 1) as well as for compositions reinforced with fibres (Fig. 4). The images were made at various magnifications. Additionally, an EDS analysis was made for chosen compositions (Fig. 5 and Table 1).

Preliminary observations confirm the regular distribution and coherency of fibres and the geopolymer matrix [29]. The SEM investigations enabled familiarisation with the overall structure of the composites and the role of fibres. A high coherence with the matrix was observed. In Fig. 4a, the fibres that are actively involved in strength transmission are visible. The cracking is limited by the presence of fibres [29]. Moreover, some fibres probably partly dissolved during geopolymerisation. The partly destroyed basalt fibre is shown in Fig. 4b.
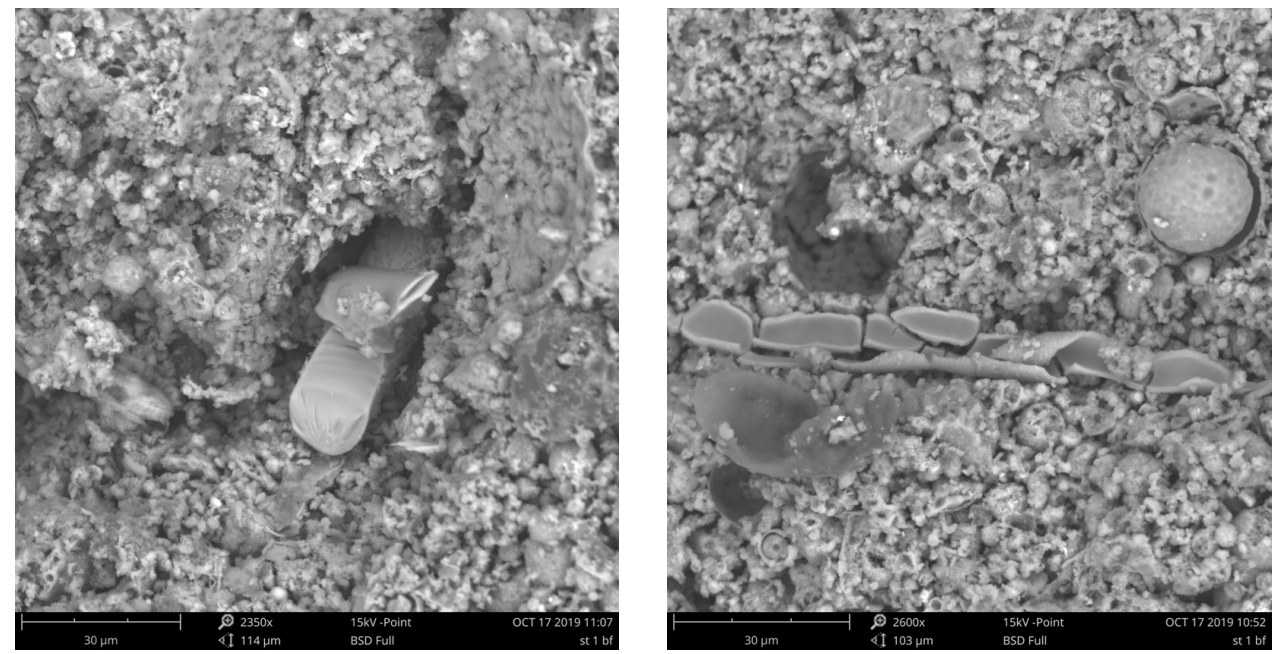

Fig. 4. Microstructure for samples reinforced by basalt fibres: a) influence of the fibre on crack propagation, b) partly dissolved basalt fibre

For the chosen samples, EDS analysis for the selected area (highlighted on Fig. 5) was conducted. 

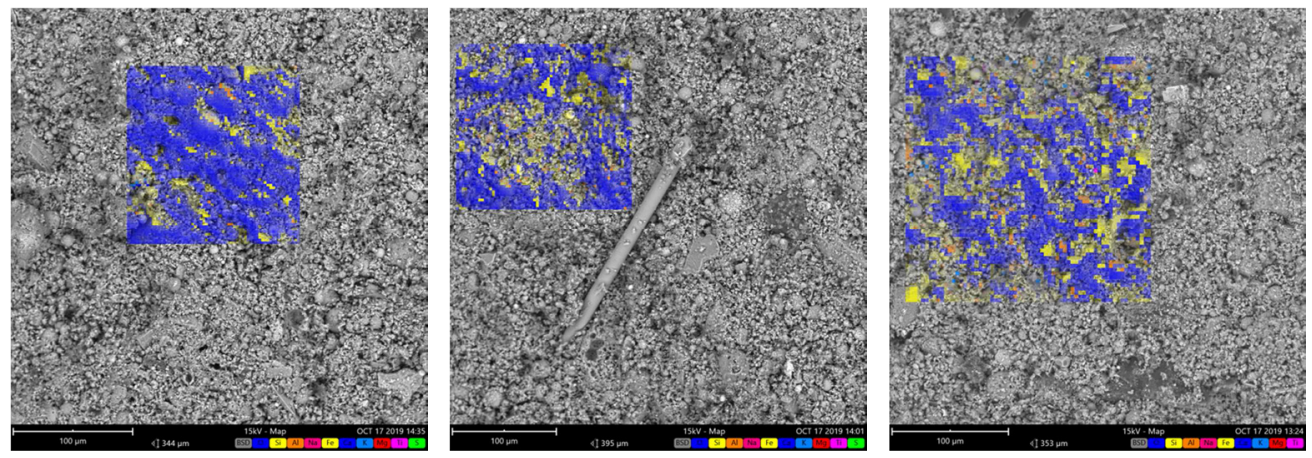

Fig. 5. Microstructure for the samples cured with different methods: a) "in air", b) submerged into water, c) half submerged

Table 1 also shows the EDS analysis for the areas presented in Fig. 5.

Table 1. Results of EDS analysis

\begin{tabular}{|l|l|l|l|l|l|l|}
\hline \multirow{2}{*}{$\begin{array}{l}\text { Element } \\
\text { name }\end{array}$} & \multicolumn{2}{|l|}{ Sample cured “in air" } & \multicolumn{2}{l|}{$\begin{array}{l}\text { Sample submerged in } \\
\text { water }\end{array}$} & \multicolumn{2}{l|}{ Sample half submerged } \\
\cline { 2 - 7 } & $\begin{array}{l}\text { Atomic } \\
\text { Conc. [\%] }\end{array}$ & $\begin{array}{l}\text { Weight } \\
\text { Conc. [wt.\%] }\end{array}$ & $\begin{array}{l}\text { Atomic } \\
\text { Conc. [\%] }\end{array}$ & $\begin{array}{l}\text { Weight } \\
\text { Conc. [wt.\%] }\end{array}$ & $\begin{array}{l}\text { Atomic } \\
\text { Conc. [\%] }\end{array}$ & $\begin{array}{l}\text { Weight } \\
\text { Conc. [wt.\%] }\end{array}$ \\
\hline Oxygen & 66.55 & 53.03 & 65.80 & 51.71 & 65.04 & 50.65 \\
\hline Silicon & 12.32 & 17.24 & 13.16 & 18.15 & 14.07 & 19.23 \\
\hline Aluminium & 8.84 & 11.88 & 9.56 & 12.67 & 9.95 & 13.07 \\
\hline Sodium & $\mathbf{7 . 9 3}$ & $\mathbf{9 . 0 8}$ & $\mathbf{6 . 3 9}$ & $\mathbf{7 . 2 2}$ & $\mathbf{5 . 7 4}$ & $\mathbf{6 . 4 2}$ \\
\hline Iron & 1.07 & 2.98 & 1.26 & 3.46 & 1.50 & 4.07 \\
\hline Calcium & 1.02 & 2.05 & 1.44 & 2.84 & 1.38 & 2.69 \\
\hline Potassium & 0.93 & 1.81 & 0.97 & 1.87 & 1.14 & 2.16 \\
\hline Magnesium & 0.89 & 1.07 & 0.91 & 1.09 & 0.92 & 1.09 \\
\hline Titanium & 0.20 & 0.48 & 0.27 & 0.63 & 0.27 & 0.63 \\
\hline
\end{tabular}

The analysis did not confirm any significant differences with regard to the elements appearance, including sodium, that should be removed during curing in water. It worth to notice that the results for light elements could be not accurate because of character of the SEM test. This results should be also confirm by other research methods.

\subsection{Mechanical properties - compressive strength}

The results of the compressive strength tests are shown in Table 2.

Table 2. The results of compressive strength after 28 days

\begin{tabular}{|l|l|l|}
\hline Sample & $\begin{array}{l}\text { Compressive } \\
\text { strength [MPa] }\end{array}$ & $\begin{array}{l}\text { Standard } \\
\text { deviation [MPa] }\end{array}$ \\
\hline Cured "in air" without fibres & 13.1 & 1.7 \\
\hline Cured "in air" - 1\% basalt fibres & 10.7 & 1.1 \\
\hline Cured "in air" - 2\% basalt fibres & 11.9 & 0.8 \\
\hline Cured "in water" without fibres & 15.3 & 1.5 \\
\hline Cured "in water" - 1\% basalt fibres & 10.6 & 2.2 \\
\hline Cured "in water" - 2\% basalt fibres & 10.9 & 2.2 \\
\hline Cured half submerged without fibres & 11.2 & N/A \\
\hline Cured half submerged - 1\% basalt fibres & 11.2 & N/A \\
\hline Cured half submerged - 2\% basalt fibres & 10.5 & N/A \\
\hline
\end{tabular}


The best results were obtained for the plain samples cured in water. After 28 days, the value of compressive strength was more than $15 \mathrm{MPa}$. The lowest value in the case of the plain material was for that which was half submerged. However, the results for the halfsubmerged samples are not statistically significant because of a lack of an appropriate number of samples.

The results achieved for composites with basalt fibres in the case of curing in water are worse than for the samples cured "in air", but the difference is very slight and it is smaller than the standard deviation. It is statistically non-significant.

The compressive strength changes should also depend upon the fibre content. The literature shows that the results for reinforced samples are usually better [29-32]. However, lower values for compressive strength for the samples with fibres have been previously reported in the literature $[29,33]$. The research also allows indirect observation of changes in the behaviours of samples. The plain basic samples were broken in brittle way, whereas for the samples with fibres, the mechanism of breaking was more ductile [29]. This behaviour was the same for all curing methods. The change of the behaviour is coherent with the research reported in the literature [29-32].

The results of the compressive strength test were then compared with the density of the samples (Table 3).

Table 3. The density of the samples after 28 days

\begin{tabular}{|l|l|}
\hline Sample & Density $\left[\mathbf{g} / \mathbf{c m}^{\mathbf{3}}\right]$ \\
\hline Cured "in air" without fibres & 1.47 \\
\hline Cured "in air" - 1\% basalt fibres & 1.44 \\
\hline Cured "in air" - 2\% basalt fibres & 1.43 \\
\hline Cured "in water" without fibres (sample after preparing) & 1.47 \\
\hline Cured "in water" without fibres (sample after 3 weeks of curing in water) & 1.62 \\
\hline Cured "in water" without fibres (sample after drying - 1 week) & 1.25 \\
\hline Cured "in water" - 1\% basalt fibres (sample after preparing) & 1.49 \\
\hline Cured "in water" - 1\% basalt fibres (sample after 3 weeks of curing in water) & 1.63 \\
\hline Cured "in water" - 1\% basalt fibres (sample after drying - 1 week) & 1.24 \\
\hline Cured "in water" - 2\% basalt fibres (sample after preparing) & 1.50 \\
\hline Cured "in water" - 2\% basalt fibres (sample after 3 weeks of curing in water) & 1.61 \\
\hline Cured "in water" - 2\% basalt fibres (sample after drying - 1 week) & 1.22 \\
\hline Cured half submerged without fibres & 1.62 \\
\hline Cured half submerged - 1\% basalt fibres & 1.59 \\
\hline Cured half submerged - 2\% basalt fibres & 1.58 \\
\hline
\end{tabular}

The density should correlate with compressive strength [29]. For the examined samples, this tendency did not appear. Nevertheless, the differences in the densities were non-significant.

\section{Conclusions}

Geopolymer composites based on fly ash reinforced with basalt fibres were produced using different curing methods. The composites were prepared using sodium promoter. Observation of the microstructure showed a regular distribution and coherence of fibres within the matrix. No differences in the applied curing method were shown with regard to the microstructure. The results for compressive strength showed slight reinforcement for the samples without fibres that were cured in water and lower values for this curing method for the samples with basalt fibres. These changes could be caused by the presence of fibres. The differences are not statistically significant. The curing "in air" and in water (submerged 
samples) did not cause efflorescence. Efflorescence appeared on the half-submerged samples.

This work has been financed by the Polish National Agency for Academic Exchange under the International Academic Partnership Programme within the framework of the grant: E-mobility and sustainable materials and technologies EMMAT and under the academic exchange programme as part of bilateral cooperation with the Czech Republic as well as with Hungary. The research has also been conducted partly through the support of the Tempus Public Foundation in the framework of the programme called Bilateral State Scholarships. The described work was carried out with the use of equipment purchased from the project: Innovative fine grinding - particle design technologies laboratory development at the University of Miskolc in the Centre of Excellence on Sustainable Natural Resources Management, GINOP-2.3.3-15-2016-00019. The project was founded in the framework of the Széchenyi 2020 Program. It was supported by the European Union, co-financed by the European Social Fund.

\section{References}

1. G. Silva, S. Kim, R. Aguilar, J. Nakamatsu, Sustainable Mat. Techn. 23, e00132 (2020)

2. P. Rożek, M. Król, W. Mozgawa, J. Cleaner Production 230, 557 (2019)

3. N. Li, C. Shi, Z. Zhang, H. Wang, Y. Liu, Comp. Part B 178, 107490 (2019)

4. A. Koleżyński, M. Król, M. Żychowicz, J. Molecular Structure 1163, 465 (2018)

5. D. Mierzwiński, J. Walter, IOP Conf. Series: Mat. Sci. \& Eng. 706, 012012 (2019)

6. R. M. Novais, R.C. Pullar, J.A. Labrincha, Progress in Materials Sci. 109, 100621 (2020)

7. N. B. Singh, Minerals 8, 299 (2018)

8. Y. Wang, X. Liu, W. Zhang, Z. Li, Y. Zhang, Y. Li, Y. Ren, J. Cleaner Production 244, 118852 (2020)

9. E. N. Kani, A. Allahverdi, J.L. Provis, Cement Concrete Comp. 34, 25 (2012)

10. K. Sun, X. Peng, S. Wang, L. Zeng, P. Ran, G. Ji, Constr. Build. Mater. 253, 118952 (2020)

11. L.-L. Kan, J.-W. Lv, B.-B. Duan, M. Wu, Cement Concrete Res. 125, 105895 (2019)

12. Z. Zhang, J. L. Provis, X. Ma, A. Reid, H. Wang, Cement Concrete Comp. 92, 165 (2018)

13. Z. Li, S. Li, Constr. Build. Mater. 254, 119069 (2020)

14. D. Mierzwiński, K. Korniejenko, M. Łach, J. Mikuła, J. Krzywda, IOP Conf. Series: Mat. Sci. \& Eng. 416, 012035 (2018)

15. Z. Zhang, J. L. Provis, A. Reid, H. Wang, Cement \& Concr. Res. 64, 30 (2014)

16. R. Xiao, Y. Ma, X. Jiang, M, Zhang, Y. Zhang, Y. Wang, B. Huang, Q. He, J. Cleaner Production 252, 119610 (2020)

17. C. R. Kaze, P. Venyite, A. Nana, D.N. Juvenal, H.K. Tchakoute, H. Rahier, E. Kamseu, U.C. Melo, C. Leonelli, Materials Chemistry \& Physics 239, 122268 (2020)

18. M. A. Longhi, Z. Zhang, E.D. Rodríguez, A.P. Kirchheim, H. Wang, Frontiers in Materials 6, 89 (2019)

19. P. N. Lemougna, U.F.C. Melo, M.P. Delplancke, H. Rahier, Constr. Build. Mater. 48, 278 (2013)

20. M. Łach, K. Korniejenko, J. Walter, A. Stefańska, J. Mikuła, Materials 13, 3 (2020)

21. M. Vafaei, A. Allahverdi, Advanced Powder Technology 28 (1), 215 (2017) 
22. T. A. Kua, A. Arulrajah, S. Horpibulsuk, Y.J. Du, C. Suksiripattanapong, Clean Technologies and Environmental Policy 19 (1), 63 (2017)

23. Y.-S. Wang, Y.Alrefaei, J.-G. Dai, Frontiers in Materials 6, 106 (2019)

24. X. Xue, Y.-L. Liu, J.G. Dai, C.-S. Poon, W.-D. Zhang, P. Zhang, Cement Concrete Comp. 94, 43 (2018)

25. H. Wan, L. Yuan, Y. Zhang, Frontiers in Materials 7, 57 (2020)

26. M.A. Longhi, E.D. Rodríguez, B. Walkley, Z. Zhang, A.P. Kirchheim, Compos Part BEng 182, 107671 (2020)

27. K. Korniejenko, N.P. Halyag, G. Mucsi, IOP Conf. Series: Mat. Sci. \& Eng. 706, 012002 (2019)

28. K. Korniejenko, M. Łach, J. Marczyk, C. Ziejewska, N. P. Halyag, G. Mucsi, IOP Conf. Series: Mat. Sci. \& Eng. 706, 012006 (2019)

29. K. Korniejenko, G. Mucsi, N.P. Halyag, R. Szabó, D. Mierzwiński, P. Louda, KnE Engineering 2020, 86 (2020)

30. G. Masi, W. D. A. Rickard, M. C. Bignozzi, A. van Riessen A., Compos Part B-Eng. 76, 218 (2015)

31. X. Guo, X. Pant X., 2018, Constr. Build. Mater. 179, 633 (2018)

32. A. Celik, K. Yilmaz, O. Canpolat., M.M. Al-Mashhadani, Y. Aygörmez, M. Uysal, Constr. Build. Mater. 187, 1190 (2018)

33. D. P. Dias, C. Thaumaturgo, Cement Concrete Comp. 27, 49 (2005) 